\title{
A surprising cause of wheezing in a morbidly obese patient: a case report
}

This article was published in the following Dove Press journal:

International Medical Case Reports Journal

21 October 2014

Number of times this article has been viewed

\section{Lakshmi N Kurnutala \\ Minal Joshi \\ Hattiyangadi Kamath \\ Joel Yarmush}

Department of Anesthesiology, New York Methodist Hospital, Brooklyn, NY, USA

Video abstract

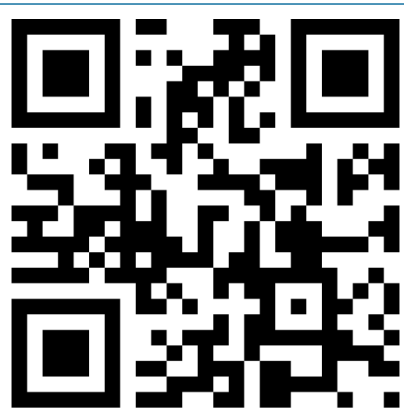

Point your SmartPhone at the code above. If you have a QR code reader the video abstract will appear. Or use: http://dvpr.es/ZQDuhG
Correspondence: Lakshmi N Kurnutala Department of Anesthesiology, New York Methodist Hospital, 506 6th Street, Brooklyn, NY I I2I5, USA Tel + I 6467240799

Fax + I 718780328 I

Email drnarasimhulu_k@yahoo.com
Abstract: A typical patient with chronic obstructive pulmonary disease has small airway disease, which often responds to bronchodilators. If the patient is obese, he or she may be further compromised and not tolerate being in the supine position. We present a case of a patient with history of chronic obstructive pulmonary disease and obstructive sleep apnea with acute renal failure and urosepsis scheduled for an emergent debridement of Fournier's gangrene. In this patient, the fiberoptic intubation was performed in semi-Fowler's position, and tracheomalacia was observed.

Keywords: tracheomalacia, difficult airway, fiberoptic intubation, COPD

\section{Case report}

A 54-year-old man who weighed $168 \mathrm{~kg}$ and was $1.75 \mathrm{~m}$ tall (body mass index, $56 \mathrm{~kg} / \mathrm{m}^{2}$ ), with a history of chronic obstructive pulmonary disease (COPD) and obstructive sleep apnea on continuous positive airway pressure for 10 years at home was admitted to the emergency department with acute renal failure and sepsis. He was scheduled for an emergent debridement of Fournier's gangrene.

The emergency physician consulted anesthesiology for intubation because of respiratory failure. As a result of the patient's history of COPD, he was unable to compensate for the metabolic acidosis that was secondary to his sepsis. Other past medical history included coronary artery disease treated with percutaneous coronary intervention and stenting, a 30 pack-year smoking history, and morbid obesity.

Physical examination in the emergency department revealed respiratory distress, tachypnea, and diffuse bilateral wheezing. Airway assessment showed a mouth opening of three finger-breadths, Mallampati airway classification 3, and a thyromental distance of $6 \mathrm{~cm}$ with a neck circumference of $44 \mathrm{~cm}$. In the sitting position, the patient's blood oxygen saturation was $99 \%$ on a fraction of inspired oxygen of 0.5 . When the patient positioned supine, he became cyanotic, with blood oxygen saturation $\sim 85 \%$ on a fraction of inspired oxygen of 0.5 , with increased intensity during inspiration with coarse, low-pitched wheezing and dyspnea. He received bronchodilators without improvement of the wheezing.

After assessing the patient, the anesthetic plan was discussed with the patient and the surgical team. An elevated prothrombin time of 24 seconds (international normalized ratio, 3.6) and septic shock contraindicated regional anesthesia. Out of concern for maintaining the patient's airway, it was felt that a general anesthetic with an awake fiberoptic endotracheal intubation in the operating room was the safest 
way to proceed. The surgical team would be immediately available for a surgical airway in case of an emergency.

In the operating room, the fiberoptic intubation was performed in the semi-Fowler's position $\left(45^{\circ}\right)$ after bilateral superior laryngeal nerve block and transtracheal instillation of 4\% lidocaine. During bronchoscopy, tracheomalacia was observed. The wheezing was completely resolved after insertion of an endotracheal tube, which stented the airway open and improved air entry. Debridement of the Fournier's gangrene proceeded. As a result of underlying septic shock with hypotension, the patient needed vasoactive agents (phenylephrine). Intraoperative arterial blood gas showed a $\mathrm{pH}$ of 7.26, a partial pressure of carbon dioxide of $34 \mathrm{mmHg}$, a partial pressure of oxygen of $320 \mathrm{mmHg}, \mathrm{HCO}_{3}^{-}$ levels of 16.0, base excess -11 , and a blood oxygen saturation of $100 \%$. At the conclusion of surgery, the patient remained intubated and transferred to the intensive care unit for further management. In the intensive care unit, the patient was treated with antibiotics and inotropic support for septic shock. Patient was receiving pressure-regulated volume control ventilation in the intensive care unit with a fraction of inspired oxygen of 1.0, a respiratory rate of 20 breaths per minute, a peak inspiratory pressure of $25 \mathrm{mmHg}$, and a positive end-expiratory pressure if $7 \mathrm{mmHg}$. The patient developed acute respiratory distress syndrome postoperatively. A computed tomography scan of the chest showed bilateral infiltrates in lung bases as a result of sepsis. On fifth postoperative day, the patient succumbed to multiorgan dysfunction, including hepatic, renal, cardiac, and pulmonary systems related to Fournier's gangrene and sepsis syndrome.

\section{Discussion}

Difficulties encountered in tracheal intubation in obese patients are associated with high morbidity and mortality related to anesthesia. ${ }^{1}$ Increased risk of difficult intubation in obese patients is associated with decreased thyromental distance $(<6 \mathrm{~cm})$, increased neck circumference $(>40$ $\mathrm{cm})$, increased body mass index $\left(>35 \mathrm{~kg} / \mathrm{m}^{2}\right)$, and a Mal-

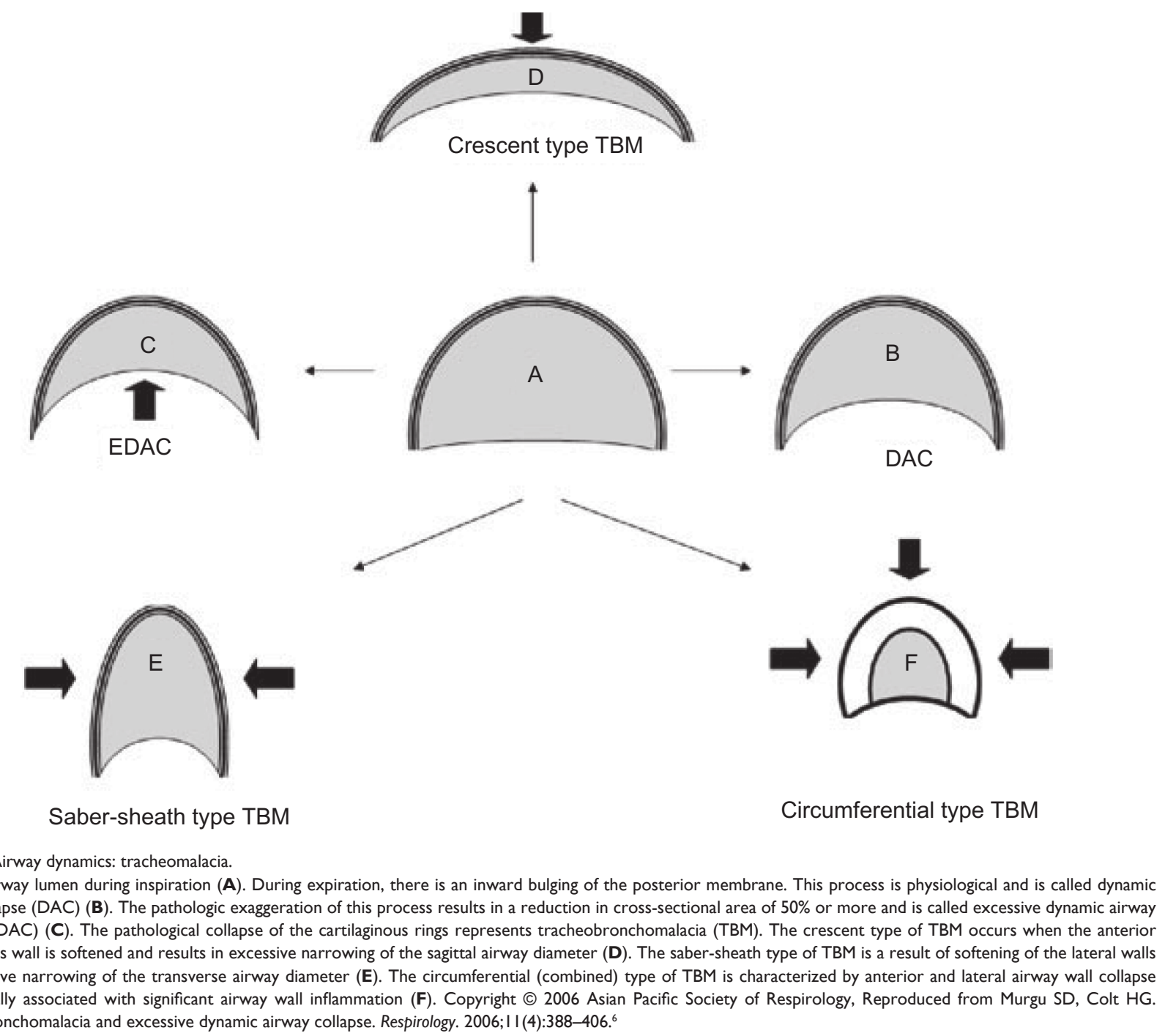

Figure I Airway dynamics: tracheomalacia.

Notes: Airway lumen during inspiration (A). During expiration, there is an inward bulging of the posterior membrane. This process is physiological and is called dynamic airway collapse (DAC) (B). The pathologic exaggeration of this process results in a reduction in cross-sectional area of $50 \%$ or more and is called excessive dynamic airway collapse (EDAC) (C). The pathological collapse of the cartilaginous rings represents tracheobronchomalacia (TBM). The crescent type of TBM occurs when the anterior cartilaginous wall is softened and results in excessive narrowing of the sagittal airway diameter (D). The saber-sheath type of TBM is a result of softening of the lateral walls and excessive narrowing of the transverse airway diameter (E). The circumferential (combined) type of TBM is characterized by anterior and lateral airway wall collapse and is usually associated with significant airway wall inflammation (F). Copyright @ 2006 Asian Pacific Society of Respirology, Reproduced from Murgu SD, Colt HG. Tracheobronchomalacia and excessive dynamic airway collapse. Respirology. 2006; I I (4):388-406. ${ }^{6}$ 
lampati airway grade higher than $2 .^{2,3}$ Optimal care includes identifying the risk for airway difficulties and planning an approach for securing the airway. ${ }^{4,5}$

Tracheomalacia is characterized by the flaccidity of the supporting cartilage and hypotonic myoelastic elements. These factors cause tracheal collapse, especially during times of increased airflow associated with increased airway dynamic pressure changes, such as coughing (Figure 1). ${ }^{6}$ It is also associated with intermittent or continuous dyspnea, difficulty in clearing secretions, cough, wheezing, pneumonia, and recurrent bronchitis.

The etiology includes genetic causes (polychondritis), posttraumatic (long-term tracheal intubation, tracheostomy, closed chest trauma, after lung transplantation), COPD, chronic external compression of the trachea (malignancy, benign tumors, cysts, abscesses, and aortic aneurysms), and vascular rings. ${ }^{6}$ Tracheomalacia related to chronic obstructive lung disease causes high-grade, chronic, long-segment airway obstruction. ${ }^{7}$ The incidence of tracheomalacia is $3 \%$ in patients with COPD. ${ }^{8}$

In patients with a difficult airway with Mallampati airway grade higher than two, increased neck circumference $(>40 \mathrm{~cm})$, with elevated body mass index $\left(>35 \mathrm{~kg} / \mathrm{m}^{2}\right)$ and a history of COPD unresponsive to bronchodilator therapy, the risk of tracheomalacia is elevated, and awake fiberoptic intubation is the best option for securing the airway. In the index patient, the endotracheal tube functioned as a stent and relieved the obstruction caused by tracheomalacia.

Flexible bronchoscopy is the gold standard method of diagnosing tracheomalacia, but it is not always feasible in settings with limited resources. In the absence of other modalities for diagnosis, fluoroscopy should be considered in the setting of persistent respiratory symptoms compatible with the clinical picture of tracheomalacia. ${ }^{9}$
Wheezing in morbidly obese COPD patients is not always caused by small airway disease. In this case, the patient had tracheomalacia and the solution for this was awake fiberoptic intubation.

\section{Acknowledgment}

The authors thank Dr Joseph SchianodiCola, Chairman, Department of Anesthesiology, New York Methodist Hospital, for providing general support to write this paper.

\section{Disclosure}

The authors report no conflicts of interest in this work.

\section{References}

1. Shiga T, Wajima Z, Inoue T, Sakamoto A. Predicting difficult intubation in apparently normal patients: a meta-analysis of bedside screening test performance. Anesthesiology. 2005;103(2):429-437.

2. Gonzalez H, Minville V, Delanoue K, Mazerolles M, Concina D, Fourcade $\mathrm{O}$. The importance of increased neck circumference to intubation difficulties in obese patients. Anesth Analg. 2008;106(4):1132-1136.

3. Brodsky JB, Lemmens HJ, Brock-Utne JG, Vierra M, Saidman LJ. Morbid obesity and tracheal intubation. Anesth Analg. 2002;94(3):732-736.

4. Benumof JL. Management of the difficult adult airway. With special emphasis on awake tracheal intubation. Anesthesiology. 1991;75(6):1087-1110.

5. Lienhart A, Auroy Y, Péquignot F, et al. Survey of anesthesia-related mortality in France. Anesthesiology. 2006;105(6):1087-1097.

6. Murgu SD, Colt HG. Tracheobronchomalacia and excessive dynamic airway collapse. Respirology. 2006;11(4):388-406.

7. Gaissert HA, Burns J. The compromised airway: tumors, strictures, and tracheomalacia. Surg Clin North Am. 2010;90(5):1065-1089.

8. Hasegawa I, Boiselle PM, Raptopoulos V, Hatabu H. Tracheomalacia incidentally detected on CT pulmonary angiography of patients with suspected pulmonary embolism. AJR Am J Roentgenol. 2003;181(6): $1505-1509$.

9. Sanchez MO, Greer MC, Masters IB, Chang AB. A comparison of fluoroscopic airway screening with flexible bronchoscopy for diagnosing tracheomalacia. Pediatr Pulmonol. 2012;47(1):63-67.

\section{Publish your work in this journal}

The International Medical Case Reports Journal is an international, peer-reviewed open-access journal publishing original case reports from all medical specialties. Previously unpublished medical posters are also accepted relating to any area of clinical or preclinical science. Submissions should not normally exceed 2,000 words or

\section{Dovepress}

4 published pages including figures, diagrams and references. The manuscript management system is completely online and includes a very quick and fair peer-review system, which is all easy to use. Visit http://www.dovepress.com/testimonials.php to read real quotes from published authors. 